\title{
Managing the Flow of Information on the Factory Floor
}

Docki Saraswati, Sumiharni Batubara, Reny Mulyadi, Amelia Mulyadi Industrial Engineering Department, Trisakti University, Jakarta, Indonesia

Em:dsrianto@cbn.net.id

Keywords Computer Integrated Manufacturing, Computer Aided Process Planning, Group Technology, Scheduling.

\begin{abstract}
This paper presents findings of a study aimed at developing a suitable information system for manufacturing feature interactions in handling manufacturing process planning. The main objective is to provide a Virtual Manufacturing System Planning based on Computer Integrated Manufacturing. It begins with the incoming parts and utilises the proposed parts database that serves as a source for the parts codification module. This module requires Computer Aided Process Planning to provide the routing plans that will identify the machines and tools required. Utilising tools and machines databases will provide the information for parts scheduling, which determines the promised delivery time.
\end{abstract}

\section{INTRODUCTION}

Controlling the factory floor has been an elusive goal for manufacturers, especially when customers are more demanding than ever before. Manufacturers should respond quickly to the demands of the customer since the product innovation cycle has changed, from manufacturer- oriented to customer-oriented market [9]. Customers take it for granted that the manufacturer will deliver a product on time. Integrating the systems on the production floor is critical to respond to the rapid and dynamic changes in the product cycle.

The aim of this research is to develop a suitable information system to handle the flow of information on the factory floor. In this regard, information technology plays a dominant role in integrating the whole system.

The proposed flow of information is divided into three parts. First, information on incoming parts, which includes the routing plan using a 
specific NC machine and tools. Second, it identifies machine availability and determines the use of tools, or vice versa. Finally, it assesses the availability of tooling to determine the relationship between the machines and tools. This allows a more systematic approach to production scheduling, which will determine the use of tooling. The interactivity will also ensure the appropriate delivery time.

On a larger scale, this study will make use of the Internet to create a forum that allows customers access to available information at a given time.

An extensive research will be conducted at an industrial plant located at the Jababeka Industrial Estate in West Java. This plant specialises in spring compression, spring extension and spring torsion.

\section{RESEARCH PROBLEM}

The current process plan in the plant is performed manually. This approach requires an experienced and knowledgeable planner who has access to data of machine availability, machine capabilities and stock availability. This also means that a planner is involved in retrieval and manipulation of a great deal of information. The result of the process plan is then manifested in the form of printed text, lists and drawing. Moreover, this approach has a great possibility of producing different routing-sheets for similar parts at different times. Therefore, the use of computer has certainly made planning more efficient [5].

This research will explore tools and machines availability. Current planning and controlling of tools for the $\mathrm{CNC} / \mathrm{NC}$ machines is done manually, using stock cards. Using these cards, the coiling production subdepartment records all the data flow of tooling. Usually, after each process is completed, the tools remain with the machines. The operator believes this is critical in saving time for when the next process comes. Unfortunately, by doing this, the coiling production sub-department does not have information on the tooling status and this presents a constraint in, or even prevents them from, making a production schedule. The transformation of tooling data into information that benefits production scheduling is therefore required.

\section{RESEARCH METHODOLOGY}

This paper is presented as part of an on-going large research project whose main objective is to gain a Virtual Manufacturing System Planning based on Computer Integrated Manufacturing (CIM), particularly on the production floor. Based on the information made available, it is possible for managers to make decisions in remote locations. Information Engineering is 
used as a methodology in applying the structures techniques to the enterprise. Its consists of 4 stages: Information Strategy Planning, Business Area Analysis, System Design and Construction [6].

The framework of research methodology is described in figure 1:

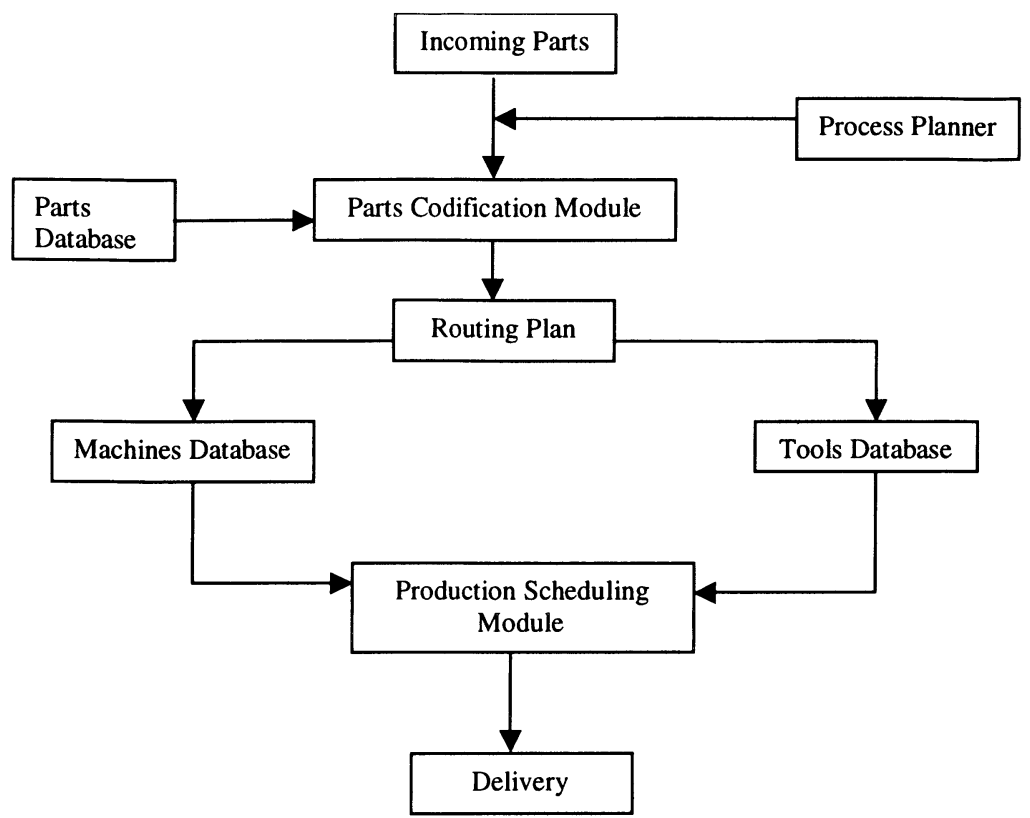

Figure 1 : Framework of research methodology

This research will be divided into three areas:

1. Parts Codification Module

2. Production Scheduling Module

3. Performance System Module

The information system is crucial in fulfilling the aim of this research. By utilising parts, machines and tools databases, the information required by a user becomes accessible. Several papers have been published on the issue, including the concepts of designing an Internet-based system for manufacturing system, managing the flow of information and redesigning it under the web-based system $[1,3,9]$.

\section{PARTS CODIFICATION}

A process planner is required to identify the incoming parts. For this purpose, integration of technologies that include $\mathrm{CAD}, \mathrm{CNC}$ or $\mathrm{NC}$ is critical. 
The incoming parts are classified into parts families, using Group Technology (GT) which is based on their similarities in design or manufacture characteristics and grouping them into part families (Heragu, 94). Depending on how the conceptual scheme is constructed, there are three major types of classification: visual method, part coding analysis and Production Flow Analysis (PFA). This research uses a part coding and classification analysis (PCA) to identify similarities. Part characteristicsbased systems form part families according to their design-based features: shapes, sizes and tolerances [7].

Further, the objective of the GT approach is to identify the grouping of parts that share common processing requirements based on their routing sheets. The available information explains the relationship between parts, machines and tools that are required to process them.

A Computer Aided Process Planning (CAPP) system is based on the GT approach, and basically constitutes two approaches, namely variant and generative. In the variant approach, the standard operating plan is identified through GT. If a new plan is required, then the existing standard plan can be retrieved and edited to meet the requirements of the new parts. There are several stages required to establish a variant approach, such as inputting existing GT codes, part process plan database, part drawing database, variant process plan generator and finally standard process plan [2]. In the generative approach, a process plan is made based on information available in the manufacturing database. This system can generate the required and sequenced operations for a new part. All information on manufacturing has to be stored as software. This system utilises decision logic as a tool to generate a process plan. Should the program detect that the information for the new part is not available in the database, then the generator system will proceed to create a new process plan, based on a GT code. This new plan is generated from the interactive input, which is done by a user. This generative approach can be divided into five stages: interactive input, generative process plan generator, operating plan rules, operating plan requirements and part drawing.

The coiling department is a workshop that employs 50 machines consisting of CNC T20 (17 units), HTC (11 units), EH CLS10 (8 units) and EH CLS16 ( 2 units). Figure 2 shows the product routing in this department.

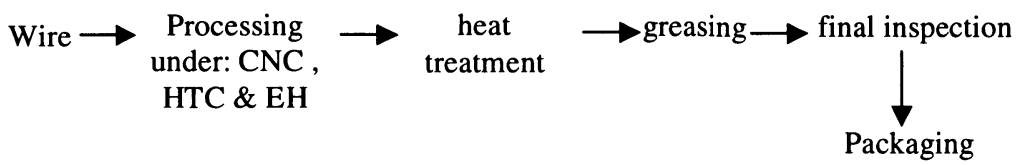

Figure 2: Product routings 
There are 3 types of machines: HTC for spring compression, EH for spring extension and $\mathrm{CNC}$ for string torsion. Based on parts specification and parts drawing, the codes for spring compression and extension consist of 19 digits, while that for spring torsion is made up of 22 digits.

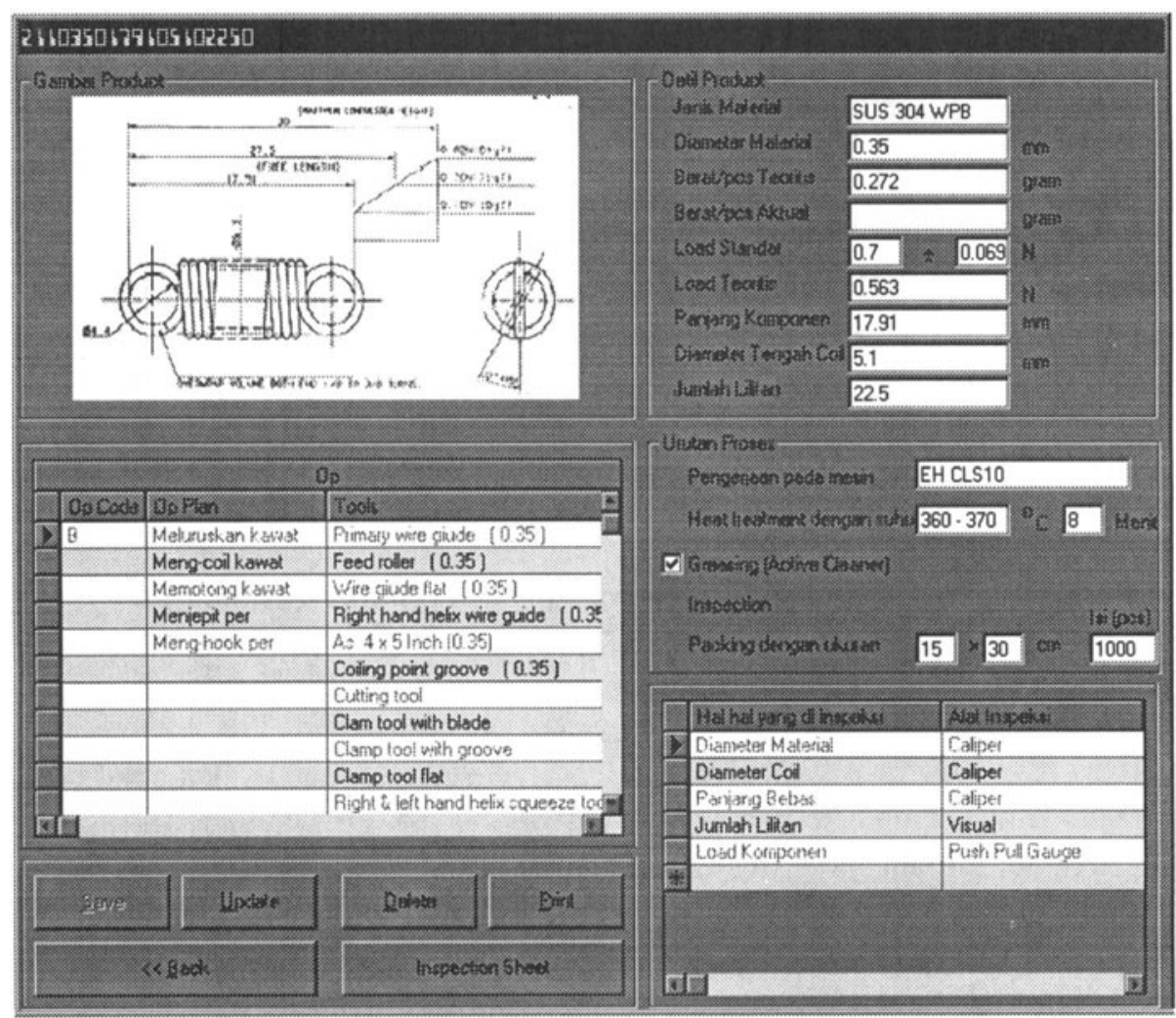

Figure 3: Part Codefication

\section{SCHEDULING}

Tool requirement for each processing on each machine is associated with part characteristics, such as the diameter of the raw material (wire), the diameter of coil and the number of bending. This means that the variability in type of tools is enormous and can cause problems in controlling the tools.

Therefore, based on the routing plan that is produced under the CAPP system, the PPIC department has to locate the assigned tools using the database. For simplification, the tools have been divided into two categories, main tools and additional tools. They are classified into 5 tool-cutting 
families, namely adapter tool (9 digits), rolls tool (6 digits), coiling tool (8 digits), bending tool ( 6 digits) and additional tools (4 digits).

After receiving an order that carries a code number, the PPIC department makes a production scheduling based on the priority sequencing rule for flexible flow shop [8]. There are several possible ways to execute the production schedule and the algorithm is as follows:

1. Check tools inventory, if tools are available, then proceed to step 2, otherwise go to step 3 .

2. Check machines availability, if the machine is idle, then go to step 4, otherwise search for the machine that will be available in the shortest time. Unload the tools, then go to step 4

3. Check tools that are attached to the machine, if it requires only one type of tool (e.g. tool a), then go to step 6, otherwise go to step 8 .

4. Setting tools to process the new parts, go to step 5

5. Process the new part according to the routing plan.

6. Check if more than one tool is required (number of tools a), set up times for when all tools are ready for the new routing plan. Select the appointed machine. Go to step 7

7. Check the types of tools that are still needed on the machine for the new routing plan, and unload unselected tools. Calculate the total time required. Go to step 9

8. Determine the types of tools that are required. Go to step 11

9. Check if there is any idle machine, otherwise go to step 10. Calculate the total time required to process the part on that idle machine (T2). If T2< $\mathrm{T} 1$, then unload tools from a selected machine. Set up tool required on the machine. Go to step 5, otherwise go to step 10

10. Unload unused tools from the machine. Set up required tools on the machine then go to step 5 .

11. Check the number of each type of tools $>1$, then go to step 12, otherwise go to step 13.

12. Determine the time when the types of tools are available, then go to step 13

13. Select the suitable machine. Choose the selected machine, then go to step 7

\section{IMPLEMENTATION}

This model is run under Visual Basic 6.0, using Microsoft access for the databases. Several data dictionaries are included, such as data dictionary for customers, delivery orders, parts knowledge-based, types of tools, tools status, etc. The scenario is implemented in 20 code parts, which is the 
delivery order part in March 2000 for the CNC $10 \mathrm{~T}$ machine. The result is measured by two performances, namely makespan and mean flow time.

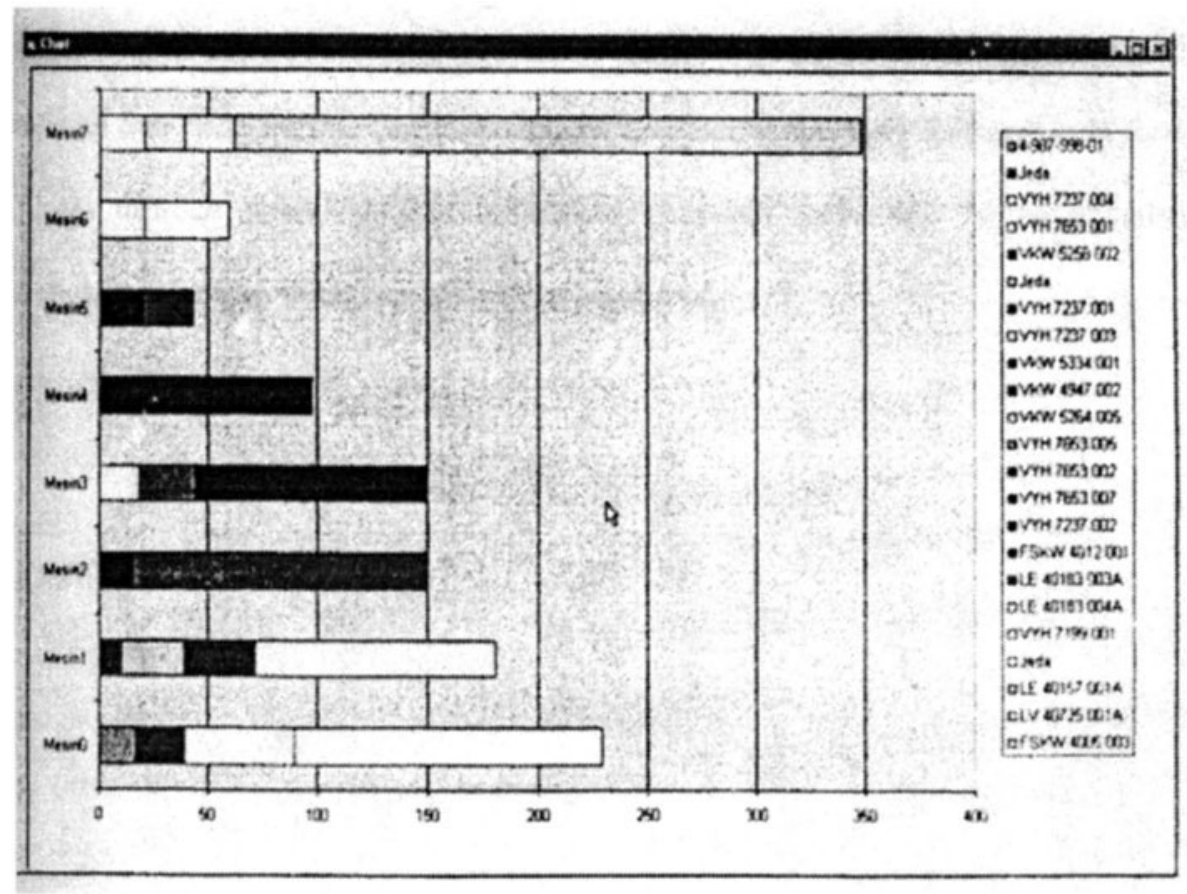

Figure 3: Submenu Form Gantt Chart

\section{CONCLUSION}

This paper describes the requirements of databases to support parts codification and scheduling based on delivery orders, machines and tools availability. Computer Aided Process Planning is used to provide parts codification. The resulting routing-plan will lead the parts to the machines and tools that are required.

\section{ACKNOWLEDGEMENT}

This research is conducted under the DCRG (Domestic Collaborative Research Grant) Program - URGE (University Research Graduate Education) Project for the Industrial Engineering Department, Trisakti University, under the supervision of Dr. Kadarsah Suryadi of the Bandung Institute of Technology (ITB). 


\section{REFERENCES}

[1] Behera, Kirt B., How to Redesign the Factory for Flow Manufacturing-Integrating Product, Process and People, APICS International Conference Proceedings, 153-157, New Orleans, LA, October 24-27, 1999.

[2] Feng, Shaw C., Chun (Chuck) Zhang, A Modular architecture for rapid development of CAPP systems for agile manufacturing, IIE Transactions, 30, 893-903, 1998.

[3] Gunasekaran, A. Agile Manufacturing: A Framework for Research and Development, International Journal Production Economics 62, 87-105, 1999.

[4] Heragu, Sunderesh S., Group Technology and Cellular Manufacturing, IEEE Transaction Systems, Man and Cybernetics, vol. 24, no. 2, 203-215, February 1994.

[5] Houtzeel, Alexander, A CAPP Perspective, Modern Machine Shop, 72-79, November 1995.

[6] Martin, James, Information Engineering: A James Martin Trilogy, I. Introduction, II. Planning and Analysis, III. Design and Construction, PHI, 1989, 1990, 1991.

[7] Offodile, O.Felix, Abraham Mehrez, John Grznar, Cellular Manufacturing: A Taxonomic Review Framework, Journal of Manufacturing Systems, vol. 13, no. 3, 196-220, 1994.

[8] Pinedo, Michael, Xiuli Chao, Operations Scheduling, with applications in Manufacturing and Services, Irwin-MGH, 1999.

[9] Wang, Z.Y., K.P. Rajurkar, A. Kapoor, Achitecture for Agile Manufacturing and Its Interface with the Computer Integrated Manufacturing, Journal of Material Processing Technology 61, 99-103, 1996. 